\title{
A self-adjusting head holder without ear-bars for guinea pigs
}

\author{
Sebastian Haidarliu ${ }^{1}$ Ehud Ahissar ${ }^{1} \cdot$ Inbar Saraf-Sinik ${ }^{1}$
}

Received: 5 February 2018 / Accepted: 10 April 2018 / Published online: 21 April 2018

(C) The Physiological Society of Japan and Springer Japan KK, part of Springer Nature 2018

\begin{abstract}
A self-adjusting head holder is designed to allow stable fixation and precise positioning (anterior-posterior, pitch, and roll) of guinea pig head in stereotaxic devices. These are achieved with no use of ear-bars. It is thus easy to use, preferable for studies of the auditory system, and for avoiding tissue damage of the ear in general. This head holder can accommodate various head sizes and is thus adapted for males and females of a large range of body weights, as confirmed for guinea pigs of 360-940 g. Moreover, this head holder is easy and cost-effective to manufacture, making it accessible for any lab. Here, we present background and mechanical rationale, the technical specifications, and step-by-step manufacturing instructions for the stainless-steel and the plastic MRI-compatible versions of our self-adjusting head holder.
\end{abstract}

Keywords Head holder $\cdot$ Teeth anatomy $\cdot$ Guinea pig

\section{Introduction}

Optical imaging, MRI, and recordings of neuronal activity in laboratory animals require immobilization of the head of anesthetized animals. Standard stereotaxic devices for small laboratory animals usually make use of ear-bars. Besides the difficulties with ear-bar insertion, which requires certain skills, the procedure can cause damage to the soft tissues of the external acoustic meatus and tympanic membrane. Ear-bar positioning may also interfere with the experimental manipulations, for example, when recordings are performed from the somatosensory or auditory cortices. To overcome such problems, different designs of head holders without ear-bars were proposed for mice [1-3], rats [4-9] and guinea pigs [10]. For non-human primates, head fixation was usually performed by surgically attached to the skull devices. Recently, for head fixation in small laboratory rodents, metallic head-holding plates are used, both in behaving [11] and anesthetized [12]. The head holder we proposed in the past for guinea pig head fixation [10] fits the unique arrangement of adult male guinea pig teeth. Specifically, the two upper masticators and the rostral part of the hard palate are positioned on the distal end of the mouthpiece, thus not

Sebastian Haidarliu

sebastian.haidarliu@weizmann.ac.il

1 Department of Neurobiology, The Weizmann Institute of Science, Rehovot 76100, Israel allowing rostro-caudal movement due to a limiting tenon. However, that head holder is compatible only with animals weighing 400-750 g, but not with lower or higher weights.

The newly proposed head holder is very simple and consists of only two components instead of five in the previous head holder version [10]. It relies on three contact points with the guinea pig skull: (1) the incisors; (2) the back of the snout; (3) the premolars. Such triangular contact arrangement provides reliable fixation of the head in anesthetized guinea pigs. To maximize its size compatibility, this head holder is designed not to be in contact with the molar teeth. Instead, only the ventral tips of the two maxillary premolars are fixed in the longitudinal grooves of the distal end plate of the mouthpiece. This design allows adjusting of the anterior-posterior position of the mouthpiece during mounting to the optimal points of the skull, where the head can be firmly fixed.

\section{Materials and methods}

\section{Anatomical features of the guinea pig snout involved in the head-holder self-adjusting mechanism}

Designing a head holder that fits guinea pig heads of different sizes, we focused on the skull structures previously proven to be good anchoring points in head-holder designs 
for mice and rats: (1) incisors; (2) back of the snout; (3) maxillary masticators and/or hard palate. The first two structures are similar in mice, rats and guinea pigs. The masticators, however, are different in guinea pigs (Cavia porcellus Linnaeus) [13], and we suggested that their unique anatomical features can be used to facilitate self-adjustment of the head holder to the animals with different head size. For this purpose, we have studied the spatial arrangement of the guinea pig teeth (incisors, maxillary premolars and molars) in 11 skull preparations obtained from the guinea pigs that were used in our previous studies [14, 15], during which the head holder described here was designed and tested. The body weights of these guinea pigs varied from 360 to $940 \mathrm{~g}$ (median, $640 \mathrm{~g}$ ). For head-holder manufacturing, two parameters of the skulls were determined: (1) the distance between the tips of the two maxillary premolars and (2) the distance between the inner side of the incisor necks and the tips of the maxillary premolars. The first parameter varied between 4 and $5.2 \mathrm{~mm}$ (median, $4.45 \mathrm{~mm}$ ), and the second, between 17 and $18.9 \mathrm{~mm}$ (median, $17.7 \mathrm{~mm}$ ).

\section{Manufacturing the mouthpiece}

The mouthpiece configuration was designed to fit the spatial arrangement of incisors and maxillary premolars within the guinea pig snout. The mouthpiece was made of a 105 -mm-long cylindrical rod, $10 \mathrm{~mm}$ in diameter, of which the 45-mm-long proximal part remained intact and served for attachment to the standard stereotaxic devices for small laboratory animals. The distal part, $60 \mathrm{~mm}$ long, was first shaped as a blank using a lathe machine (Fig. 1a). Then, the blank was tapered towards the distal end by grinding its opposite sides. The distal end of the mouthpiece was shaped as a plate (end plate), $6 \mathrm{~mm}$ long, $9 \mathrm{~mm}$ wide and $3.5 \mathrm{~mm}$ thick. On this plate, two parallel longitudinal $90^{\circ} \mathrm{V}$-grooves, $\alpha$ and $\beta$, were made such that the distance between $\alpha$ and $\beta$ is $4.45 \mathrm{~mm}$, each at a depth of $2.5 \mathrm{~mm}$ and length of $6 \mathrm{~mm}$ (inset to Fig. 1). The medial walls of the grooves meet to form a ridge $(\gamma)$ of under $\sim 75^{\circ}$ angle. The dorsal edge of the ridge was smoothed to prevent oral mucous membrane from damage. The grooves are designed to fit the tips of the maxillary premolars and to prevent any movement of the guinea pig head.

To accommodate the incisors, a 5-mm-wide hole was drilled $18 \mathrm{~mm}$ from the distal end of the mouthpiece (Fig. 1b). Its edges were smoothed and polished to avoid tissue damage to the gingiva and the mucous membrane during mounting, when the incisors are wedged into this hole. To attach the adjusting bolt that controls the distance between the distal ends of the mouthpiece and snoutpiece, an obround hole, $3 \mathrm{~mm}$ wide and $8 \mathrm{~mm}$ long, was prepared with the center $45 \mathrm{~mm}$ from the tapered end of the mouthpiece. To attach the adjusting bolt to the mouthpiece, two holes were drilled perpendicular and projecting to the center of the obround hole: one hole was $3 \mathrm{~mm}$ in diameter, the other was drilled $2.5 \mathrm{~mm}$ in diameter, then tapped with a $3 \mathrm{M}$ tap, so that the attaching bolt is fixed without a nut. To form an articulated joint between snoutpiece and mouthpiece, a 3-mm-wide hole was drilled $60 \mathrm{~mm}$ from the distal end of the mouthpiece.

\section{Manufacturing the snoutpiece}

The blank for the snoutpiece was made of a stainless-steel plate $(2 \times 50 \times 60 \mathrm{~mm})$ as shown in Fig. 2a. The distal end of the snoutpiece should be projected to the middle of the distance between the hole for the incisors and the center of end plate. It was slightly widened and bent such that it can be positioned parallel to the dorsal surface of the snout (Fig. 2b). The bottom surface of the distal end was curved to form a saddle-shape that fits the back of the snout. The ends of the upright bar were bent to embrace the mouthpiece.

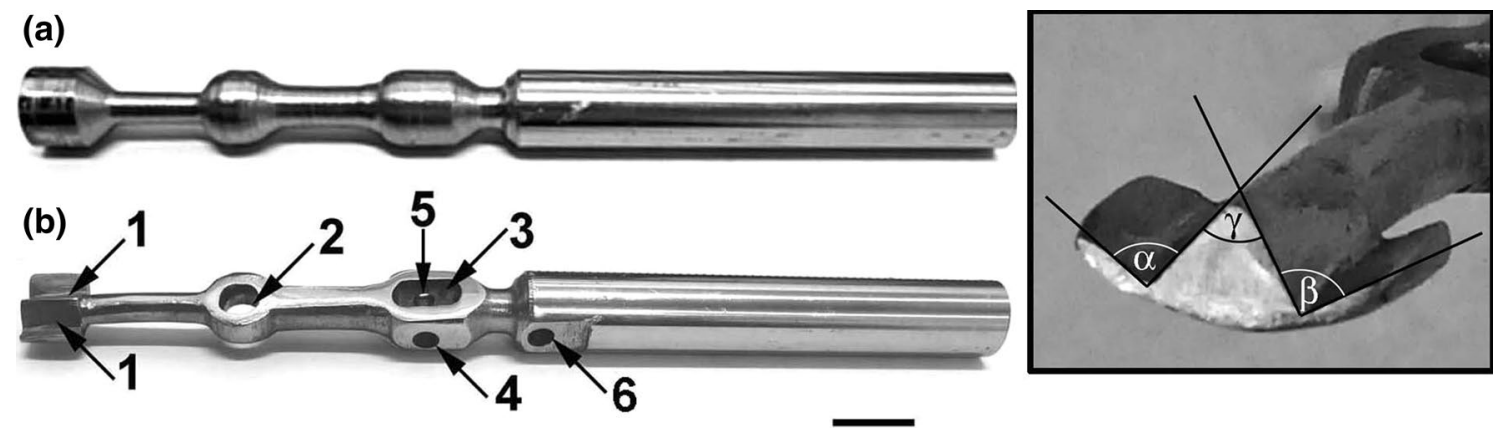

Fig. 1 Stages of the mouthpiece manufacturing. a Blank; b manufactured mouthpiece. 1 Grooves; 2 hole for incisors; 3 obround hole for attaching the bolt that controls the distance between distal ends of the snoutpiece and mouthpiece; 4 and 5 holes for the bolt that controls head-holder opening ( 4 has a $3 \mathrm{~mm}$ diameter, 5 is supplied by $3 \mathrm{M}$ thread; 6 hole for the bolt that attaches mouthpiece to snoutpiece. Scale bar $=10 \mathrm{~mm}$. Inset front view of the distal end of the mouthpiece. $\alpha, \beta$ Angles of the grooves; $\gamma$ angle formed by medial walls of the grooves (ridge) 


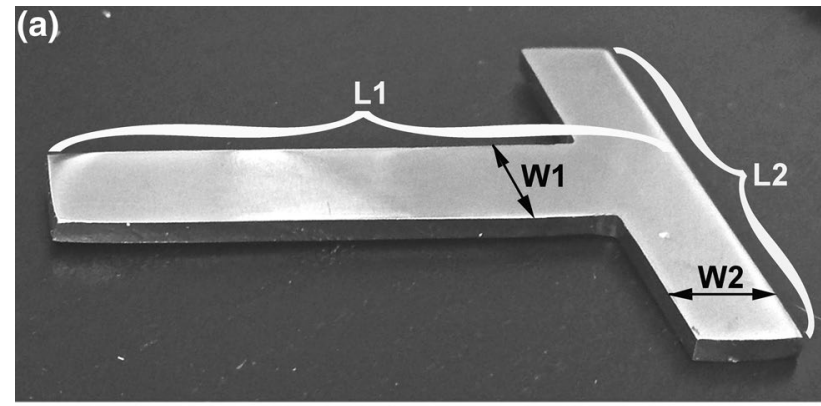

(b)

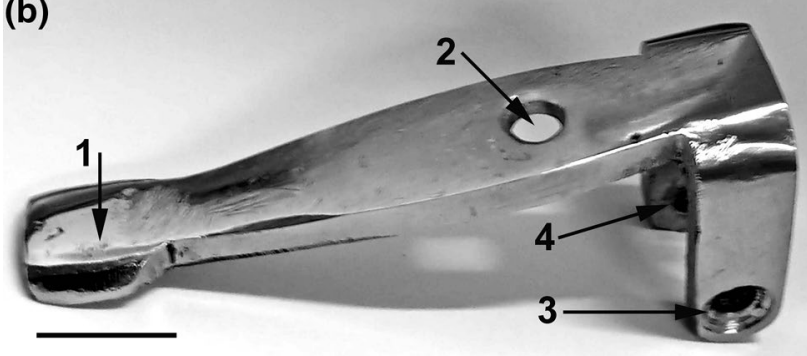

Fig. 2 Manufacturing the snoutpiece. a Blank. $L 1$ and $L 2$ represent the length (60 and $50 \mathrm{~mm}$, respectively), and $W 1$ and $W 2$, the width (10 and $8 \mathrm{~mm}$, respectively) of the top and upright bars. b Manufactured snoutpiece. 1 Distal platform that is shaped to fit the back of the guinea pig snout; 2 hole for the bolt that controls snoutpiece pressure; 3 and 4 hole and thread M3, respectively, for the bolt that connects the snoutpiece with the mouthpiece. Scale bar $=10 \mathrm{~mm}$

Finally, three holes were drilled: two holes at the ends of the upright bar for the bolt that connects the snoutpiece with the mouthpiece (one was $3 \mathrm{~mm}$ in diameter, the other was supplied by $3 \mathrm{M}$ thread), and a top hole ( $3 \mathrm{~mm}$ in diameter) for the bolt that controls the pressure exerted over the snoutpiece.

\section{Results}

\section{Spatial arrangement of the guinea pig masticators}

Studying the spatial organization of the maxillary masticators in the guinea pig skulls, we revealed the following anatomical features: (1) the plane in which the tips of the two rows of maxillary masticators lie is under an angle of $\sim 20^{\circ}$ relative to the line that connects the necks of the incisors with the tips of the most rostral masticators, i.e., premolars (Fig. 3); (2) the occlusal planes of the maxillary masticators are directed ventro-lateral and form a near right angle with their medial surfaces (Fig. 4); (3) the vertex of this angle is directed ventral; (4) the premolars possess long strong roots that make them suitable for reliable head fixation; (5) the ventral tips of the maxillary premolars are at a distance of $\sim 4.5 \mathrm{~mm}$ from each other, while the tips of the most caudal molars are distanced by $\sim 11.8 \mathrm{~mm}$ from each

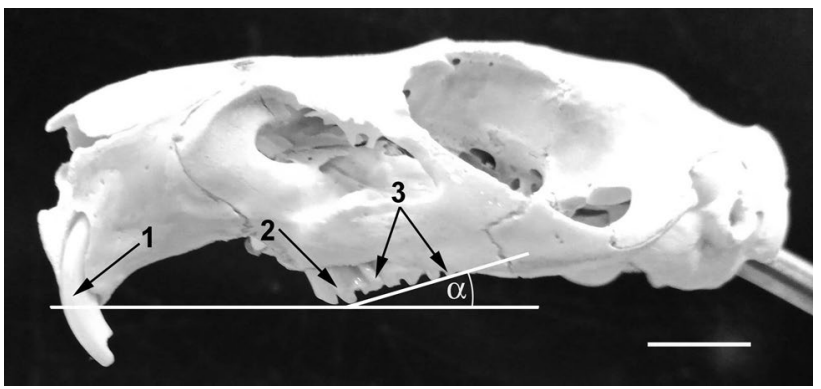

Fig. 3 Spatial relationships between incisors and maxillary masticators. $\alpha$ The angle between the plane of teeth fixation by the mouthpiece and the plane of the arrangement of the tips of maxillary masticators. 1 Incisors; 2 premolars; 3 molars. Scale bar $=10 \mathrm{~mm}$

other, so that the rows of the maxillary masticators form an angle of $\sim 38^{\circ}$ (Fig. 5), and the molars do not interfere with the axial movement of the mouthpiece when it is moved to adjust to the guinea pig head size.

The unique arrangement of the maxillary masticators allows reliable fixation of the guinea pig head using the incisors, the back of the snout, and the tips of the maxillary premolars as the third anchoring point. Adding two parallel longitudinal grooves to the end plate of the mouthpiece allows the tips of the premolars to slide along the grooves until the incisors wedge into the hole. In this position, the head can be fixed by lowering the snoutpiece.

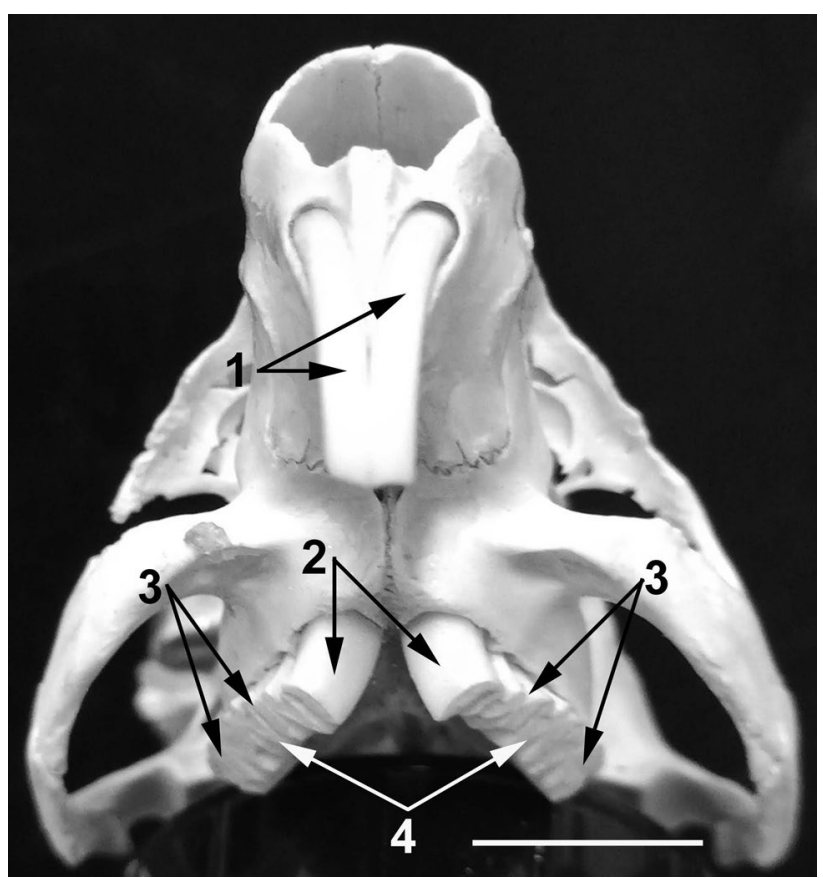

Fig. 4 Rostro-ventral view of the guinea pig teeth. 1 Incisors; 2 premolars; 3 molars; 4 occlusal planes of the maxillary masticators. Scale bar $=10 \mathrm{~mm}$ 


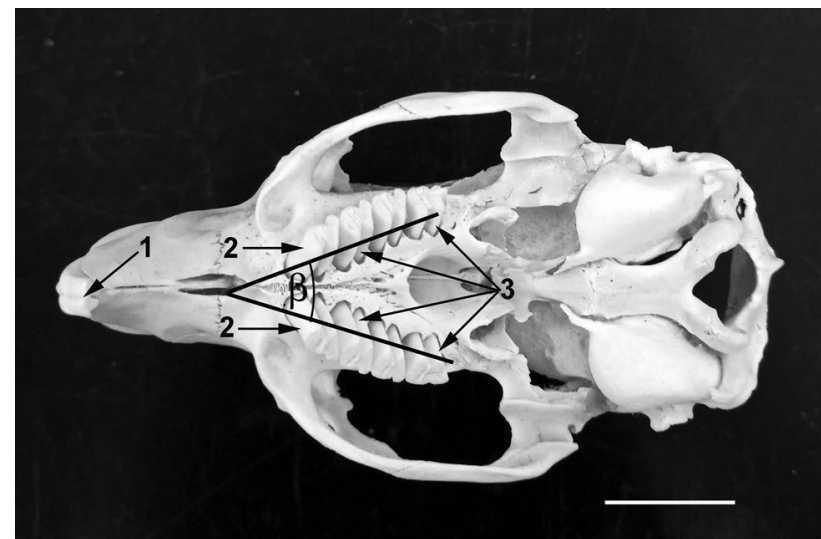

Fig. 5 Angular arrangement of the maxillary masticators. 1 Incisors; 2 premolars; 3 molars; $\beta$ the angle formed by two rows of maxillary masticators. Scale bar $=10 \mathrm{~mm}$
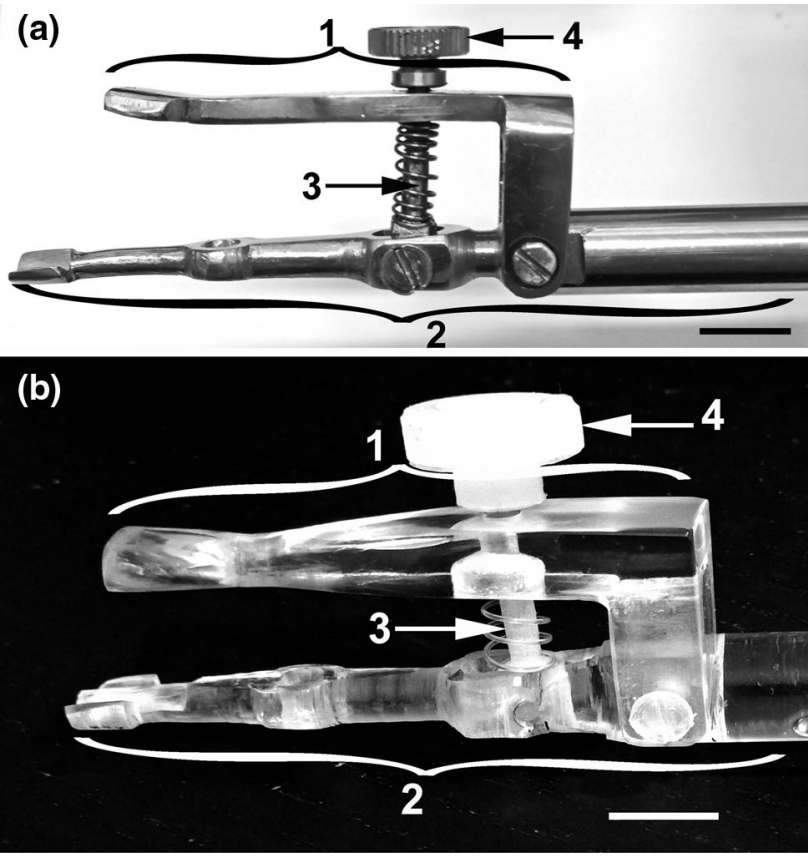

Fig. 6 Assembled head holders. a Stainless-steel version; b MRIcompatible version. 1 Snoutpiece; 2 mouthpiece; 3 adjusting bolt; 4 nut of the adjusting bolt. Scale bars $=10 \mathrm{~mm}$

\section{Assembling the head holder}

The mouthpiece and the snoutpiece were assembled together as shown in Fig. 6a. In a similar way, an MRIcompatible head holder was manufactured using a Plexiglas rod and a plate (Fig. 6b). Prior to mounting of the guinea pig head on the head holder, the guinea pig should be anesthetized. The mouthpiece is gently inserted into the guinea pig mouth until the grooves, at the distal end of the mouthpiece, touch the ventral tips of the premolars. Next,

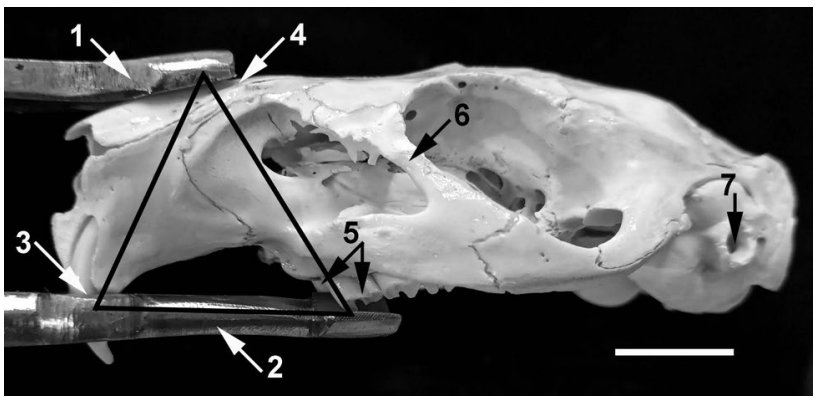

Fig. 7 Triangular fixation of the guinea pig skull by the head holder in sagittal plane. 1 Snoutpiece; 2 mouthpiece; 3 neck of the incisors; 4 dorsal surface of the snout (nasal bones); 5 maxillary premolars; 6 zygomatic arch; 7 entrance to the external acoustic meatus. The vertices of the triangle indicate the places of head fixation to the head holder. Scale bar $=10 \mathrm{~mm}$

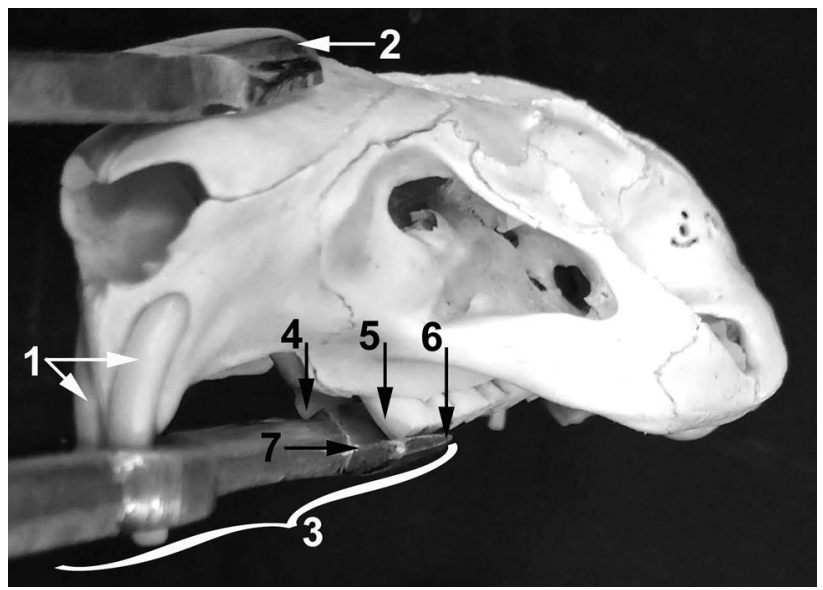

Fig. 8 Rostro-lateral view of the maxillary premolar contact with the end plate of the mouthpiece. 1 Incisors; 2 distal end of the snoutpiece; 3 mouthpiece; 4 right and 5 left maxillary premolars; 6 distal end of the mouthpiece; 7 the groove for the left premolar

the mouthpiece is advanced until the incisors slide into the hole. The snoutpiece is then lowered until its distal end touches the back of the nose, and the nut of the adjusting bolt is tightened to fix the head in this position.

When the head holder is holding the guinea pig head, the necks of incisors, the tips of the premolars, and the back of the snout form a triangular fixation of the skull to the head holder (Fig. 7). Such triangular contact of the skull with the head holder facilitates reliable fixation of the guinea pig head in the sagittal plane independently of the head size.

Figure 8 illustrates relationships between anatomical features of the premolars and the grooves on the distal end of the mouthpiece. Note that only the premolars are in contact with the relevant grooves on the mouthpiece end plate. As can be seen, the premolars can occupy a more rostral or 
a more caudal position within the grooves if the head is smaller or larger, respectively.

Under experimental conditions, the head of anesthetized guinea pig is mounted on the head holder and then transferred into the stereotaxic device. The smooth end of the mouthpiece is attached to the relevant clamping unit of the stereotaxic device, and the skull is aligned using the stereotaxic coordinates of the device.

\section{Performance of the head holder}

The evaluation of the utility of any head holder is based on its ability to perform reliable head fixation and on its compatibility with animals of a large variety of body weights. For head holders that are designated for recording of neuronal activity in laboratory animals, stable and continuous head fixation is critical. For these head holders, the duration and stability of single unit recording is a very important indicator, as well as maintaining precise spatial relationships between recorded units when multiple brain penetrations are performed. The stability of head holding depends on the spatial position of the skull structures that are in contact with the head holder, while avoiding tissue deformation. In our head holder, head fixation is based on contacts with solid structures of the skull: the incisors, the premolars and the back of the nose (nasal bones), which form an approximately equilateral triangle in the sagittal plane (see Fig. 7). The compatibility of the head holder with a large range of guinea pig body weights is due to the grooves on the distal end of the mouthpiece, where the ventral tips of the premolars can be fixed at any point along 6-mm-long grooves. The efficiency, stability, and reliability of this head holder were proven in two separate published studies that were conducted with different aims.

In the first study, the aim was to investigate the spatial organization and functional vibrissal representation of barrels in the posteromedial barrel subfield using multiple precise electrode penetrations and brief neuronal recordings [14]. The head of each anesthetized guinea pig was fixed by the head holder without ear bars we describe here, placed into Narishige (Japan) stereotaxic device, and arrays of four electrodes were lowered into the somatosensory cortex perpendicularly to its surface. Mapping of the barrel field was performed according to neuronal responses to mechanical stimulations applied to different individual whiskers. The location of each penetration was determined in relation to the bregma by direct measurements with an ocular-micrometer and by mapping on an enlarged photograph of the superficial blood vessels of the particular brain being studied. Upon completion of the recording of neuronal responses, recording sites were marked by passing electrical currents through the tips of the electrodes, inducing lesions. These lesions were then visualized in brain slices, by staining for cytochrome oxidase activity, and used to reconstruct the map of penetrations in each experiment.

The aim of the second study was revealing the dynamics of the neuronal activity in the auditory cortex of the guinea pig in response to local iontophoretic application of acetylcholine and its muscarinic agonist carbachol [15]. For this aim, single penetration recordings of neuronal activity that are stable and long-lasting were imperative. An apparatus for such recordings and simultaneous iontophoretic drug application was used. While this apparatus could be used only vertically, the lateral location of the auditory cortex required turning of the head in order to achieve recording along cortical columns. Our head holder allowed turning of the head such that the actual penetration by the apparatus was perpendicular to the cortical surface. Basic data of these two studies are summarized in Table 1.

Functional mapping of the brain structures by using multiple cortical penetrations and brief recording sessions, as well as measuring the effect of drag application by using a single penetration and continuous recording of neuronal activity were successful due to the stability of head fixation. Coupling of the head holder with a standard stereotaxic device allowed positioning of the electrodes perpendicular to the brain surface and electrode advancing through a single cortical column.

Table 1 Performance of the head holder in two studies [8, 15]

\begin{tabular}{|c|c|c|c|c|c|c|c|c|c|}
\hline Study & $\begin{array}{l}\text { Num- } \\
\text { ber of } \\
\text { animals }\end{array}$ & $\begin{array}{l}\text { Minimal } \\
\text { body weight } \\
\text { (g) }\end{array}$ & $\begin{array}{l}\text { Maximal } \\
\text { body weight } \\
(\mathrm{g})\end{array}$ & $\begin{array}{l}\text { Duration of } \\
\text { the experi- } \\
\text { ment (h) }\end{array}$ & $\begin{array}{l}\text { Total } \\
\text { number of } \\
\text { recorded } \\
\text { units }\end{array}$ & $\begin{array}{l}\text { Total num- } \\
\text { ber of single } \\
\text { units }\end{array}$ & $\begin{array}{l}\text { Duration of } \\
\text { stable unit } \\
\text { recording }(\mathrm{h})\end{array}$ & $\begin{array}{l}\text { Number of } \\
\text { mapped sites } \\
\text { per animal }\end{array}$ & $\begin{array}{l}\text { Distance } \\
\text { between } \\
\text { mapped sites } \\
(\mu \mathrm{m})\end{array}$ \\
\hline $\begin{array}{l}\text { Anatomy of } \\
\text { cortical } \\
\text { representa- } \\
\text { tions }\end{array}$ & 41 & 360 & 760 & $1-2$ & - & - & - & $\geq 20$ & $\sim 300$ \\
\hline $\begin{array}{l}\text { Recording } \\
\text { of cortical } \\
\text { neuronal } \\
\text { activity }\end{array}$ & 38 & 380 & 940 & $\begin{array}{l}10 \text { on aver- } \\
\text { age }\end{array}$ & 291 & 94 & $0.5-3.5$ & - & - \\
\hline
\end{tabular}




\section{Discussion}

The idea to use head holders without ear-bars for head fixation in small laboratory animals is not new. In about all head holders proposed up to date, the incisors and the back of the nose are commonly used as points for head fixation. For a third fixation point, some studies used the hard palate $[6$, 7, 9] and others the masticators [2, 5, 8, 16]. Manufacturers of stereotaxic equipment also proposed clamp-like head holders for mice and rats [David Kopf Instruments (Models 920-E and 921-E); Narishige (Models SH-14 and SH-16)]. Only one model was designed to fix the guinea pig head (Narishige, Model SH15, a special-order item). All these head holders have a common mechanism of head fixation: a clamp-like pressing of the snoutpiece against the mouthpiece, thereby allowing access to the animal's head from all directions, except from the rostral. To gain access from the rostral direction, Fried and colleagues [17] constructed a U-shaped head holder with four pairs of bolts applied to the sides of the skull. An original design of the head holder without ear bars for rats was proposed by Heimer and colleagues [4], who fixed the head with two needles tightened onto the posterior part of the occipital bone. To accommodate variations in head size, Frommer [5] offered a modification of the Erickson's [16] head holder for rats that consisted of additional bolts that control the distance between the flanges of the mouthpiece. In another study [7], adaptation to the animal size was implemented by using two head holders with different mouthpieces: one for rats weighing up to $250 \mathrm{~g}$, and the second for rats weighing up to $500 \mathrm{~g}$. The compatibility of our head holder with different head sizes is based on a new principle. It allows the premolars to slide in rostro-caudal direction along the grooves until reaching the optimal position corresponding to the head size of the individual animal. At this position, the head is fixed. This head holder makes contact with solid sites of the skull that are resistant to pressure: incisors, premolars, and the back of the nose (nasal bones), thus achieving stable continuous and reliable head fixation without damaging any soft tissue.

Acknowledgements This work was supported by the Israel Science Foundation (Grant no. 1127/14). EA holds the Helen Diller Family Professorial Chair of Neurobiology.

Author contributions SH and IS-S designed the head holder model and worked out all the technical details. SH manufactured the device and performed its experimental testing. IS-S drafted the manuscript with input from all authors. EA initiated and supervised the project. All authors discussed the results and contributed to the final manuscript.

\section{Compliance with ethical standards}

Conflict of interest The authors declare that they have no conflict of interest.

Ethical approval This article does not contain any studies with animals performed by any of the authors.

\section{References}

1. Jones GB, Wahlsten D, Blom G (1977) Precision stereotaxic procedure for the mouse (Mus musculus): method and instrumentation. Physiol Behav 19:445-448

2. Kučera P (1970) A new stereotactic instrument for brain operations in laboratory rodents (Muridae). Brain Res 17:499-505

3. Slotnick BM (1972) Stereotaxic surgical techniques for the mouse. Physiol Behav 8(1):139-142

4. Heimer L, Kuikka V, Larsson K, Nordstrom E (1971) A headholder for stereotaxic operations of small laboratory animals. Physiol Behav 7:263-264

5. Frommer GP (1971) Modified nontraumatic headholder. Behav Res Meth Instrum 3:225-226

6. Gray DS, Cheung BS (1982) An inexpensive surgical headholder for the rat. Physiol Behav 28:181-182

7. Hosko MJ (1972) An improved rat headclamp for neurosurgery or electrode implantation. Physiol Behav 9:103-104

8. Kaplan JM, Allan RW, Wolf G (1983) Rat stereotaxic surgery without earbars. Physiol Behav 30:975-977

9. Szlávik L, Tóth S (1974) New headholder for sensory stimulation and stereotaxic operations in small animals. Physiol Behav $13: 849-853$

10. Haidarliu S (1996) An anatomically adapted, injury-free headholder for guinea pigs. Physiol Behav 60:111-114

11. Guo ZV, Hires SA, Li N, O'Connor DH, Komiyama T, Ophir E, Huber D, Bonardi C, Morandell K, Gutnisky D, Peron S, Xu N-I, Cox J, Svoboda K (2014) Procedures for behavioral experiments in head-fixed mice. PLoS One 9(2):e88678

12. Aoki Y, Nishimura $Y$, Hondrich T, Nakayama R, Igata H, Sasaki T, Ikegaya Y (2017) Selective attenuation of electrophysiological activity of the dentate gyrus in a social defeat mouse model. J Physiol Sci 67:507-513

13. Legendre L (2016) Anatomy and disorders of the oral cavity of guinea pigs. Vet Clin North Am Exot Anim Pract 19:825-842

14. Haidarliu S, Ahissar E (1997) Spatial organization of facial vibrissae and cortical barrels in the guinea pig and golden hamster. J Comp Neurol 385:515-527

15. Shulz DE, Cohen S, Haidarliu S, Ahissar E (1997) Differential effects of acetylcholine on neuronal activity and interactions in the auditory cortex of the guinea-pig. Eur J Neurosci 9:396-409

16. Erickson RP (1966) Nontraumatic headholders for mammals. Physiol Behav 1:97-98

17. Fried H-U, Linnig H-D, Korsching SI (2001) An inexpensive mouse headholder suitable for optical recordings. Physiol Behav $74: 253-255$ 